The BDJ News section accepts items that include general news, latest research and diary events that interest our readers. Press releases or articles may be edited, and should include a colour photograph if possible. Please direct your correspondence to the News Editor, Arveen Bajaj at the BDJ, The Macmillan Building, 4 Crinan Street, London N19XW or by email to bdj@bda.org

\section{Periodontal therapy and pregnancy}

In light of new research, pregnant women may want to consider a periodontal evaluation as part of their prenatal care. A study published in the latest issue of the Journal of Periodontology shows that periodontal treatment significantly reduced the risk of having a pre-term birth or a low birthweight infant. 'We found a significant association between gingivitis and preterm birth after adjusting for the major risk factors for pre-term delivery, suggesting that gingivitis, the earliest form of periodontal disease, is an independent risk factor for pre-term birth and low birthweight,' said Dr Néstor J. López, Professor of the University of Chile. 'Periodontal therapy reduced pre-term birth and low birth-weight infant rates by $68 \%$ in women with pregnancy-associated gingivitis.' This is in concordance with two other intervention studies in which periodontal treatment reduced the incidence of pre-term births and low birth weight infants between $71 \%$ and $84 \%$ in pregnant women with moderate to severe chronic periodontitis. 'Ideally, women should begin their pregnancy without periodontal infections, and they should be educated and motivated to maintain a high level of oral hygiene prior to and throughout pregnancy,' said López. 'If periodontal infection is diagnosed at any time during pregnancy, the treatment should be administered as soon as possible in order to reduce the risk of pre-term birth and low birthweight.' In spite of this interesting finding, the mechanisms involved in the association between periodontal infections and pre-term birth remains a mystery.

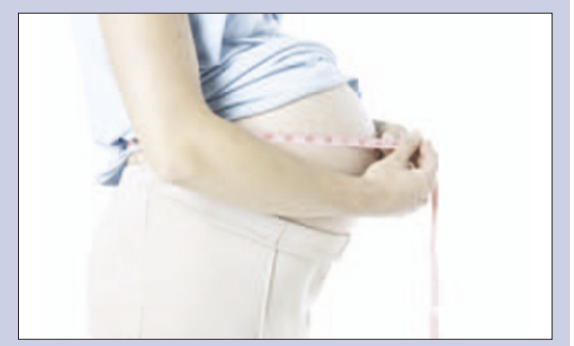

\section{Professor Blinkhorn receives $\mathrm{OBE}$}

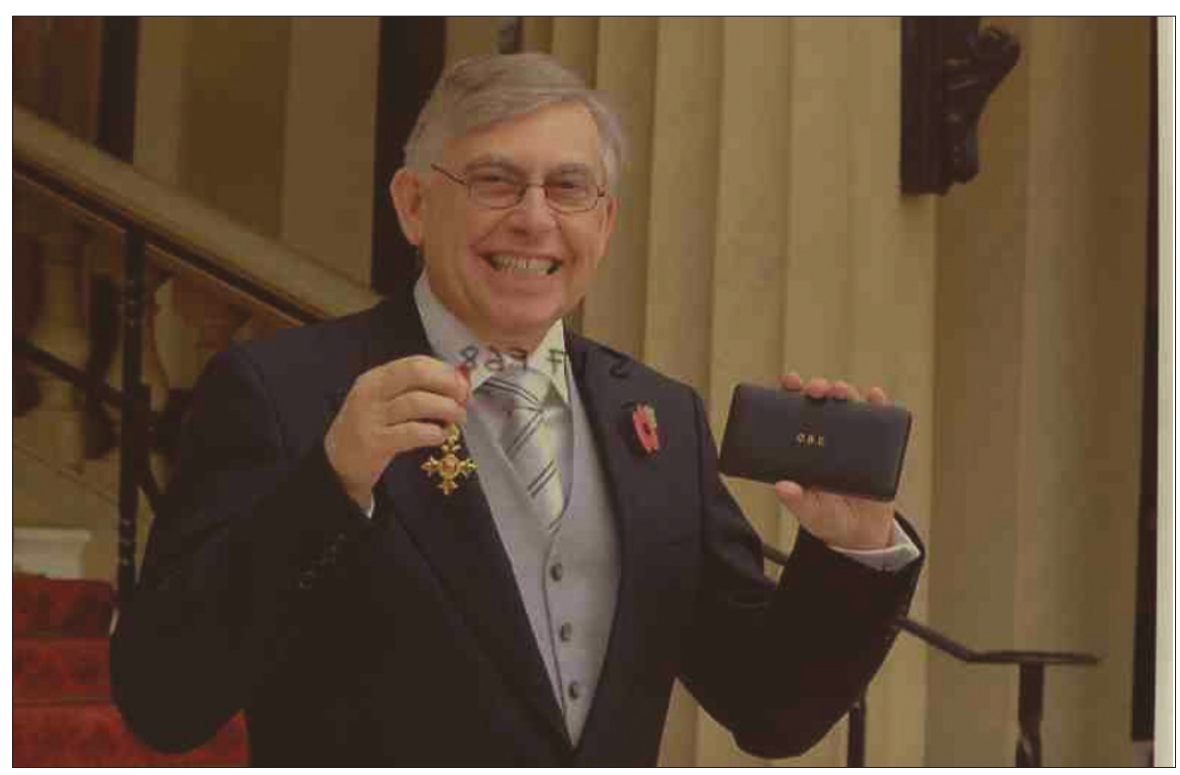

Professor Anthony Blinkhorn was appointed OBE in the Queen's Birthday Honours for his services to dentistry. This achievement recognises his commitment to developing and delivering better dental services for all patients, especially for children with medical or physical handicaps and learning difficulties. Professor Blinkhorn has also played a pivotal role in changing the way dental teaching is delivered to undergraduates. He has advocated teaching in primary care as a way of increasing clinical experience and gaining an understanding of how general dental services are delivered.

\section{Call for dental books and journals}

Are you wondering what to do with your dental books and journals when you have finished with them? Dental text-books and journals are urgently required by dental schools in the Commonwealth developing countries, particularly in Africa. The Commonwealth Dental Association (CDA) is facilitating this scheme. If you have any text books or journals that you would like to donate please contact Julia Campion, Administrator, Commonwealth Dental Association JuliaCampion@cdauk.com or telephone 02072293931 for information on where to send them in the United Kingdom for onward despatch overseas.

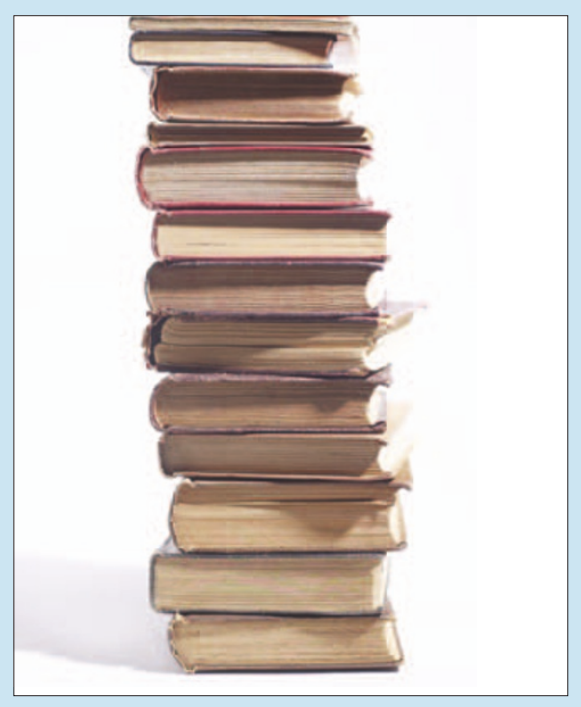




\section{Scottish children brush away tooth decay}

Parents throughout Scotland are being advised to focus on early prevention of childhood tooth decay in new NHS guidelines launched on the 24 November. Problems with decaying baby teeth often trigger a lifetime of dental treatment. Children in the most deprived communities are three times as prone to the disease and also a third less likely to have decay-free mouths at five years of age than those from wealthier areas. Overall, young children in Scotland still have one of Europe's highest rates of dental decay. However, the study shows that if parents start children brushing twice a day with a smear of medium-strength fluoride toothpaste (1000 parts per million of fluoride) this is about $25 \%$ more effective in preventing decay than non-fluoride brushing and can prevent decay.

Children older than two years are less likely to swallow toothpaste and should brush with a pea-sized amount at the same strength. Spitting rather than rinsing with water also helps the fluoride keep working, especially after bed-time brushing. Evidence uncovered shows that if parents supervise their children's tooth brushing this lessens both the amount of toothpaste used and swallowed, and further lowers the risk of decay. Brushing should start as soon as teeth start appearing which is also the key time for a child's first visit to the dentist. The guidelines, developed by the Scottish Intercollegiate Guidelines Network (SIGN) for the NHS, are available on the SIGN website (www.sign.ac.uk ) and include information for parents and carers.

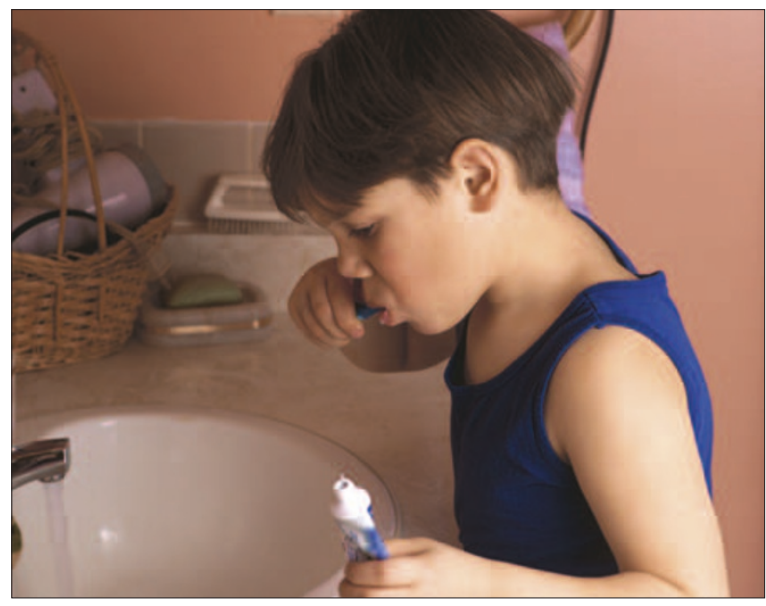

\section{British Society of Periodontology Spring meeting}

The Spring meeting of The British Society of Periodontology (BSP) will be held at Keble College, Oxford from March 24-26, including two overnight stays. The BSP is encouraging people to book early, as there is limited accommodation at the college. The meeting, called 'Blame the bugs, or blame the patient?', will look at the relative importance of microbial and patient factors in periodontitis and periimplantitis. Speaking at the event will be Professor William Wade (noted for his work on the genome of the total oral microbiota), Professor Mike Martin, Roy Page, Professor Tord Berglundh and Ubele van der Velden. The annual dinner will be to Keble's renowned catering standards and preceded by a champagne reception. For further details or to book online visit http://www.bsperio.org.uk/index.htm.

\section{Amendment to GDC schedule}

In the previous issue of the $B D J$ (issue 10), we ran an article about the GDC's call for views on fitness-to-practise guidance. The report said that the GDC planned to consult on the guidance documents in two phases - one starting in December and the other in March.

This has now been amended. The GDC will consult on all sets of guidance in one go next year. The consultations will be posted their website www.gdc-uk.org.

\section{Cranberries fight bacteria}

Dental researchers in the US have discovered that cranberries hold important clues for preventing cavities. A team led by oral biologist Hyun Koo, at the University of Rochester Medical Center has discovered that the same traits that make cranberry juice a powerful weapon against bladder infections also hold promise for protecting teeth against cavities. Koo found that cranberry juice makes it difficult for the bacteria Streptococcus mutans to cling to tooth surfaces. 'Scientists believe that one of the main ways that cranberries prevent urinary tract infections is by inhibiting the adherence of pathogens on the surface of the bladder. Perhaps the same is true in the mouth, where bacteria use adhesion molecules to hold onto teeth,' Koo said. Koo's team also found evidence that cranberry juice disrupts the formation of glucan, the building block of plaque. Streptococcus mutans uses enzymes known as glucosyltransferases to build dental plaque piece by piece. Koo's team found that cranberry juice prevents bacteria from forming plaque by inhibiting the enzyme. In spite of these promising results, Koo does not advocate mass consumption of cranberry juice, which is loaded with sugar and high in acidity, instead, he hopes to isolate the anti-cavity compounds within the juice. The substances could then be added to toothpaste or mouth rinse directly. He is working closely with Nicholi Vorsa, $\mathrm{PhD}$, a plant pathologist and director of the Blueberry and Cranberry Research and Extension Center at Rutgers, to isolate the compounds in juice that are most protective. The cranberry research will be published in the January 2006 issue of Caries Research.

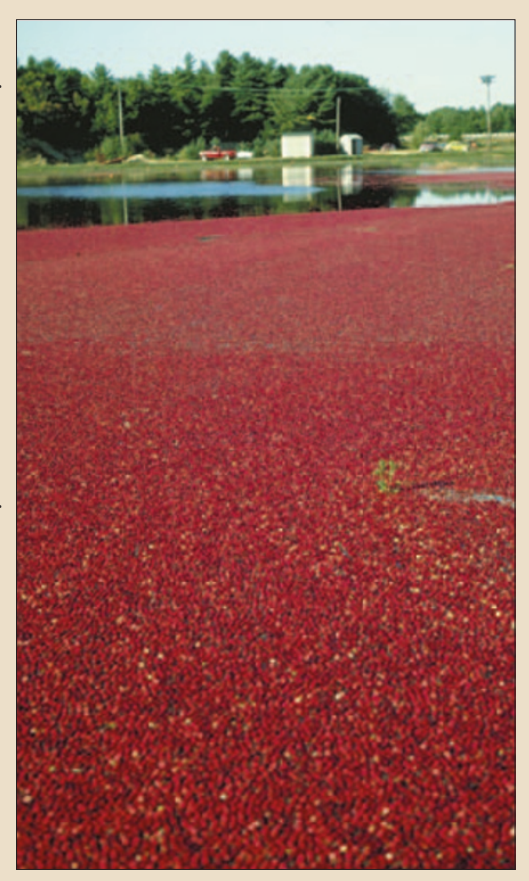




\section{Rishma Shah wins Bonjela award}

Dr Rishma Shah has won the British Orthodontic Society Audit Prize 2005. The $£ 3,000$ award is given for clinical excellence. The prize was available to full members of the British Orthodontic Society (BOS) and co-workers of the BOS wishing to carry out a clinically related project of value to the orthodontic speciality

Dr Shah's paper 'An audit of cross infection measures in Orthodontics: are you clean enough?' is a clinically related audit project. Dr Shah is currently in the second year of her fixed term training appointment and is working at both Ashford Hospital and the Eastman Dental Institute. She is also working towards a $\mathrm{PhD}$ which is an essential part of her clinical academic training. She said: 'I am delighted to have won the prize and to have the opportunity to carry out a worthwhile project that will be of benefit to clinical staff and, most importantly, patients.' Rishma will have her paper published in the BOS Newsletter.

Dr Shah receives her award

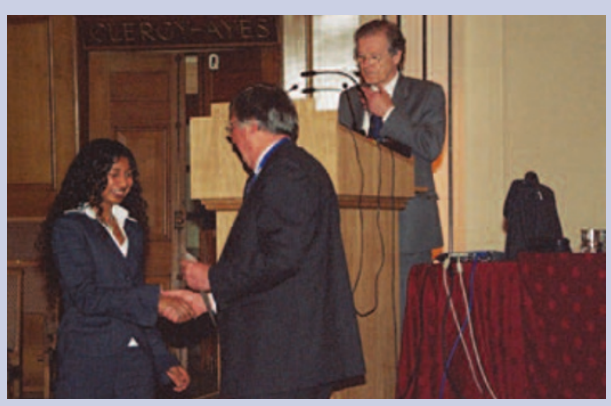

\section{Computer systems upgrade}

Dentists are being urged to check that the finance contracts for their dental practice computer systems allow for upgrades, in anticipation of the new contract introductions on 1 April 2006. With inadequate time for software companies to test their new programs and the necessity for many practices to replace or update their systems so that they can cope with the demands of the new contracts, most practices are aware of the possible computer glitches that may arise. Many, however, will not have considered the financial implications.

Jonathan Smith of Siemens Financial Services Professions Division, says, 'There is a real prospect that the profession may have to revert to a paper system as a back up as, despite their best efforts, IT providers may struggle to have fully tested systems in place for 1st April. Many practices will need to upgrade their IT software and so it is essential that they check with their finance provider that the agreement they have in place includes an upgrade option facility. If it doesn't, then we urge dentists to speak to their finance provider to understand how they can invest in new technology without increasing the monthly cost.'

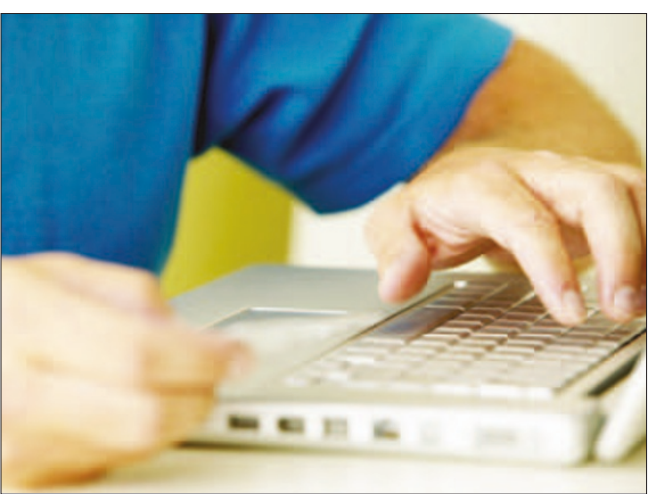

\section{Murder enquiry Torquay}

In 2001 Saraya Broadhurst (also known as Saraya Towfighi or Towfigi) went missing from her home in Torquay, Devon. On the 7th November 2005, following information from local residents, an excavation was carried out at the address from which Saraya went missing. Human remains of a white female were discovered

\begin{tabular}{|l|l}
\hline buried in the garden of this address. \\
Attempts to identify Saraya's dentist have \\
to date proved negative. It is urgently \\
requested that dentists check their records \\
and, if Saraya was ever registered at their \\
practice, contact Detective Sergeant Ivor \\
Lloyd of Devon and Cornwall Police on \\
tel. 01803 841244. It is known that Saraya \\
lived in Torbay, London and Brighton \\
in the recent past, before her disappear- \\
ance. The case is being treated as a mur- \\
der enquiry. Saraya was born on 15th \\
December 1962.
\end{tabular}




\section{Grin and bear it}

Later this month, dentist Paul Cassar, is taking time out from his practice in Chichester to fly to India to perform pioneering surgery on rescued dancing bears. Cassar of Grange Dental Surgery is a trustee of the charity International Animal Rescue (IAR) which rescues bears from the streets of India and rehabilitates them in a sanctuary in Agra, near the Taj Mahal. Paul and Lisa Milella, a vet, are both volunteering their time to carry out root canal treatment on the bears. They will also be training Indian vets at the sanctuary to treat other bears with similar problems in future. It was discovered only recently that some of the bears at the rescue centre were suffering from deep cavities where their teeth had been broken. Dancing bears in India have their teeth broken off with a hammer when they are only young cubs to make them easier to control and protect their handlers from being bitten. The remaining roots become inflamed and infected, causing intense pain, but are left untreated by the Kalandar nomads who use the bears to beg money from tourists. Cassar has gone to great lengths to research how best to treat the bears and to acquire the specialist tools for the job. 'I've had to learn a whole new set of skills to prepare for the surgery on the bears, and I've been practising by operating on the mouths of dogs like bull mastiffs which have the closest canine equivalent to the mouth of a sloth bear,' says Cassar. 'I've also managed to get hold of essential veterinary dental equipment which we have sent over in advance. As an IAR trustee, I'm keenly interested in the charity's work, and I'm delighted at this unique opportunity to really make a difference to the bears by using my own professional skills and experience.' www.iar.org.uk.

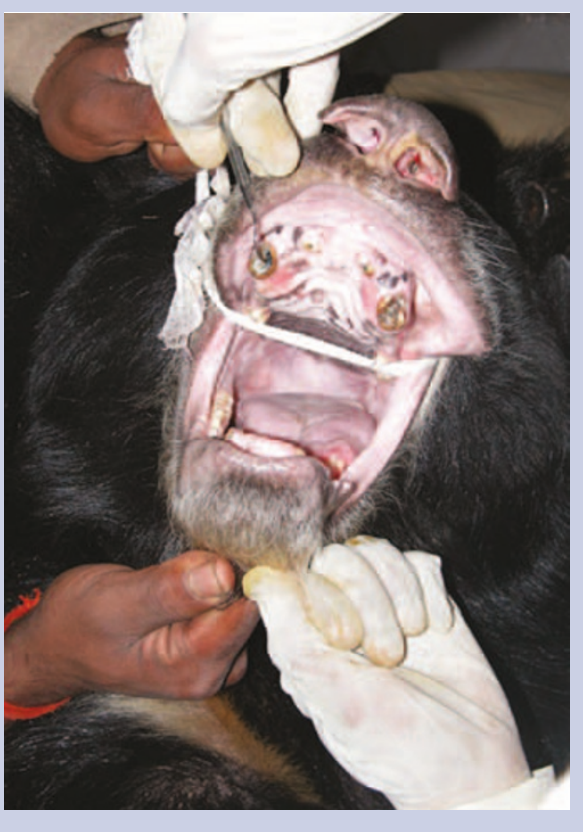

\section{Oral health room}

A special oral health room in an Oldham health centre is helping families look after their teeth and freeing up time for dentists.

The room was set up at Cannon Street health centre in June. Since then dental nurses have seen more than 450 families in special sessions designed to help them learn about oral health and hygiene.

The room is designed to have a fun and friendly atmosphere for children, and up to three families can be seen at the same time by the dental nurses. This means dentists, hygienists and dental therapists can spend more time treating patients, because the dental nurses encourage families to understand the best way of avoiding problems with their teeth, is to look after them.

Delphine Gratrix, clinical director for community dental services, decided to set the service up as part of Oldham Primary Care Trust's work to improve oral health, especially of young children. And an evaluation is now being set up to measure how successful it has been. Delphine said: 'We want to give people knowledge and motivate them to look after their teeth. This service helps to show families the importance of good oral health so they can see the value of self-help in the home. A dentist can't wave a magic wand and make things better; families need to look after their children's teeth to keep them healthy.' She added: 'Most of the children are now brushing their teeth more regularly as a result of the advice and they enjoy the sessions.'

Families attend two sessions where dental nurses show children and parents how to brush their teeth, and encourage them to do it twice a day using family fluoride toothpaste. In the second session families are given advice on healthy eating and they are encouraged to substitute sugary drinks and foods for sugar free. The children also get a toothbrush and toothpaste to take home.

The government has launched Choosing Better Oral Health, an oral health action plan for England. The action plan identifies the information and services that will enable people to take control of their oral health.

One of the aims is to improve oral health through the advice and support that dentists and other members of the dental team give their patients regarding risks such as reducing sugar consumption and giving up smoking.

\section{New GDC member appointed}

David Murphy has been appointed by the NHS Appointments Commission to serve as the lay member of the General Dental Council (GDC) for Northern Ireland. David Murphy is currently Deputy Secretary of NILGOSC (the Northern Ireland Local Government Pension Scheme). Previously he held positions with Methodist College, Grant Thornton, and Queen's University Belfast. He is a Fellow of the Institute of Chartered Accountants in Ireland. David fills the vacancy created by Brian Coulter's resignation from the GDC earlier this year. His term of office runs from 1 November 2005 to 31 October 2009. On being appointed, David Murphy said, 'Good quality dental services are a matter of importance for all of us so I am especially glad to be representing the public of Northern Ireland on the Council and assisting it with its vital work in a time of change.' Hew Mathewson, President of the GDC, welcomed Murphy on board.

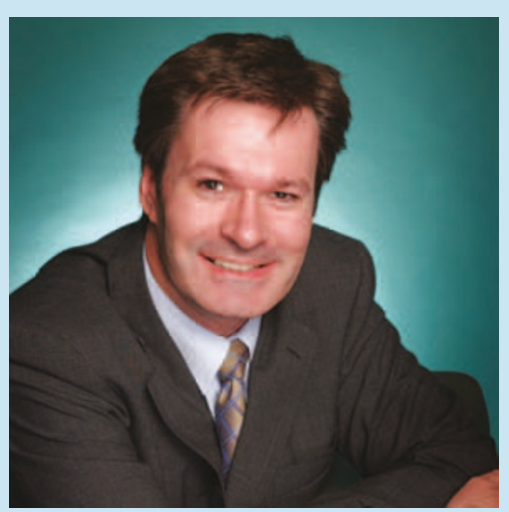




\section{One drug tackles two diseases}

Drugs that reverse and prevent bone loss due to osteoporosis also significantly ward off periodontal disease, according to a graduate of the Case Western Reserve University School of Dental Medicine who reports in the current Menopause journal article, Periodontal Assessments of Postmenopausal Women Receiving Risedronate. During her graduate studies at Case, Leena Bahl Palomo conducted one of the first studies to look at the impact of a group of bisphosphonates therapies for women with moderate and mild cases of osteoporosis and periodontal disease. The study involved 60 postmenopausal women, who had been diagnosed with osteoporosis by doctors at University Hospitals of Cleveland and who had visited the Case dental clinics. She compared the women, who had been on daily or weekly bisphosphonate for at least three months to regenerate bone mass to those on no medications for the disease. The women were between the ages of 51 and 79 and had T scores on bone scans of the hip or spine of 22.5. Half the group weighed approximately 127 pounds, and the overall study participants had similar alcohol and coffee daily intakes.

The study participants did not smoke or use tobacco or oestrogen products or have chronic medical conditions like diabetes that would increase the risks of periodontal disease. The risedronate group reported a higher use of vitamins and calcium supplements. Each woman received an x-ray of the teeth and jaw and an oral examination that assessed the amount of inflammation, depth of the periodontal pocket, recession of the gums, mobility of the teeth and the presence of plaque. The examiner was unaware of who took medication. In five of the six parameters, the risedronate therapy group had healthier periodontal status. Gingival recession was not significantly different for either group. The therapy group had significantly less plaque.

'We found a significant difference between the women who used the medications from the women who did not,' said Palomo. 'In the same way that the bisphosphonate is helping to prevent hip and vertebral fractures, the medications also prevent the loss of bone in the jaws the bones which support the teeth.'

Because bone loss is a silent disease, and is many times diagnosed in older women after a hip or bone fracture, the researcher said dentists have the opportunity to observe signs of osteoporosis during a dental exam and can refer patients for a bone scan.

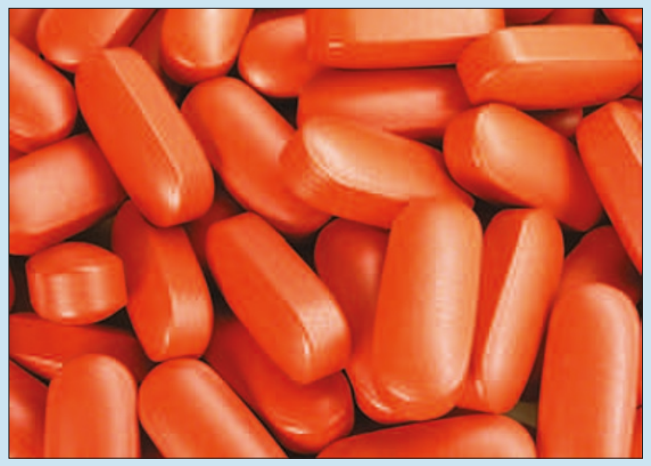

\section{The perfect filling}

What makes a good filling? A study by the University of Birmingham shows that the success of a filling could be significantly affected by the patient's age, the age of the dentist and even where the patient lives. Fillings inserted in Wales proved more long lasting than those inserted in England. Regional variations in England were less obvious, although fillings inserted in the north of England lasted least well. Surprisingly, the presence of fluoride in water made no difference to the survival of fillings. The series of studies by Professor Trevor Burke from the University of Birmingham's School of Dentistry and Dr Steve Lucarotti from the Dental Practice Board, Eastbourne, looked at more than 80,000 payment claims from the General Dental Service covering over a decade of dentistry. The data were analysed to determine how long fillings survive before the next treatment, taking into account information about patients, their dentists and the location and timing of the work. Burke's team also found that that the age

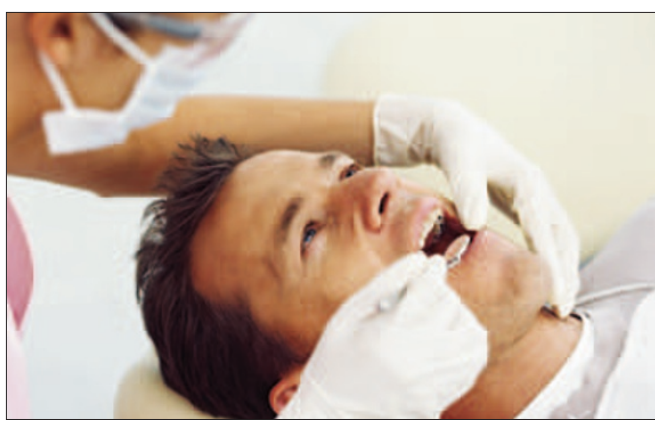
of your dentist can have an impact on the quality of dental work. Fillings placed by older dentists lasted less well than those of their younger colleagues, although the reasons for this may not be completely straightforward. There was no difference in the performance of fillings between male and female dentists. The findings will be published as a series of articles in the Journal of Dentistry.
December 2005

HealthPraxisAsia's First International Medical + Dental Symposia on chronic diseases stalking Asians

Date 16-18 December 2005.

Venue Carlton Conference Center at The Ritz-Carlton Kuala Lumpur

Tel. Cyril Jonas at + 60178819748

www.healthpraxisasia.com

February 2006

2nd European Conference of Preventitive and Minimally Invasive Dentistry

Date: 23-25 February 2006

Venue: Congress Centre Innsbruck, Innsbruck, Austria

Email: Kongress@quintessenz.de www.quintessenz.de/ecp April 2006

IDEM 2006 exhibition and conference Date: 7-9 April 2006

Venue: Suntec Singapore International Convention and Exhibition Centre www.idem-singapore.com

May 2006

British Dental Conference and Exhibition Date: 18-20 May 2006

Venue: ICC Birmingham www.bda-events.org

September 2006

FDI Annual World Dental Congress

Dates: 22-25 September 2006

Venue: SZCEC, Shenzhen Convention \& Exhibition Center, China congress@fdiworldental.org

October 2006

BDTA London Dental Showcase

Dates: 5-7 October 2006

Venue: ExCel London

www.bdta.org.uk

American Dental Association 147th Annual Session

Dates: 16-19 October 2006

Venue: Las Vegas

www.ada.org 